\title{
UMA CONTEXTUALIZAÇÃO ACERCA DA FORMAÇÃO DO PROFESSOR FRENTE ÀS TEORIAS E CONCEPÇÕES PEDAGÓGICAS CONTEMPORÂNEAS
}

\author{
A CONTEXTUALIZATION ABOUT TEACHER TRAINING FACING CONTEMPORARY \\ PEDAGOGICAL THEORIES AND CONCEPTIONS
}

\author{
Laine Marques dos Santos Almeida Bertáo \\ Prefeitura Municipal de Barra do Bugres, Mato Grosso, MT, Brasil.. E-mail: laine.marques.bertao@ \\ gmail.com
}

\begin{abstract}
Maria Luiza Barreto
Secretaria do Estado de Educação do Mato Grosso, Barra do Bugres, MT, Brasil. E-mail: barretomarialuiza47@gmail.com
\end{abstract}

DOI: https://doi.org/10.46550/amormundi.v2i7.135

Recebido em: 09.11.2021

Aceito em: 29.12.2021

\begin{abstract}
Resumo: Para possibilitar o processo de transformação na educação, faz-se necessário ao professor reconhecer o fenômeno educativo como um processo relacional, contextual e intencional. No entanto, tal ato não é algo espontâneo na natureza, não é mera aprendizagem natural, que se nutre dos materiais culturais que os rodeiam, mas uma invenção dirigida, uma construção humana que tem sentido e que leva consigo uma seleção de possibilidades, de conteúdo e de caminhos. Diante dessa realidade, este artigo traz uma contextualização acerca da formação do professor frente às teorias e concepçóes pedagógicas contemporâneas. Assim, na intenção de viabilizar a pesquisa, utilizou-se alguns autores que versam sobre a temática, tais como: Libâneo (1990), Luckesi (1996), Nóvoa (1996), Macedo (2007) e Silva (2009). E, a partir da reflexão proposta por meio da pesquisa bibliográfica desenvolvida, é possível afirmar que é de suma importância promover a contínua reflexão sobre o trabalho desenvolvido pelo pedagogo frente à sala de aula, prezando sempre pelo processo de construção da aprendizagem integral do aluno.
\end{abstract}

Palavras-chave: Formação do Professor. Teorias e Concepçôes Pedagógicas. Aprendizagem.

Abstract: To enable the transformation process in education, it is necessary for the teacher to recognize the educational phenomenon as a relational, contextual and intentional process. However, such an act is not something spontaneous in nature, it is not mere natural learning, which is nourished by the cultural materials that surround them, but a directed invention, a human construction that makes sense and takes with it a selection of possibilities, of content and of paths. In light of this reality, this article provides a contextualization of teacher education in light of contemporary pedagogical theories and conceptions. Thus, in order to make the research feasible, some authors who deal with the theme were used, such as: Libâneo (1990), Luckesi (1996), Nóvoa (1996), Macedo (2007) and Silva (2009). And, from the proposed reflection through the developed bibliographical research, it is possible to affirm that it is of paramount importance to promote continuous reflection on the work developed by the pedagogue in front of the classroom, always valuing the process of construction of the student's integral learning.

Keywords: Teacher Training. Theories and Pedagogical Conceptions. Learning. 


\section{Introduçáo}

$A_{\text {conhecer e efetivar teorias que valorizam a formaçáo do pensamento crítico, a partir }}^{\text {partir deste tema, objetiva-se promover a reflexão sobre a necessidade de o professor }}$ da participação ativa do aluno no contexto da sala de aula. Todavia, é preciso considerar que os indivíduos não nascem educadores, mas tornam-se na medida em que se educam, também no contato com o outro, sendo este um processo permanente de apropriação, mediação e transformação do conhecimento e construção da identidade docente.

Para possibilitar esse processo de transformação, faz-se necessário ao professor reconhecer o fenômeno educativo como um processo relacional, contextual e intencional. No entanto, tal ato não é algo espontâneo na natureza, não é mera aprendizagem natural, que se nutre dos materiais culturais que os rodeiam, mas uma invenção dirigida, uma construção humana que tem sentido e que leva consigo uma seleção de possibilidades, de conteúdo e de caminhos.

Nesse sentido, é preciso entender que a formação docente não se dá exclusivamente no contexto da formação inicial, mas com continuidade ao longo do trabalho, sendo esta nomeada de formação continuada ou em serviço. Logo, este artigo científico apresenta tal compreensão mediante os desafios que surgem no dia a dia do ensino em sala de aula. Apresentando a trajetória docente como um constante processo de apropriação de conhecimentos a oportunizarem o entendimento do cotidiano da escola e a ampliação do conhecimento dos estudantes.

Portanto, de modo geral, o desenvolvimento do artigo traz uma contextualizaçáo acerca da formação do professor frente às teorias e concepções pedagógicas contemporâneas com informaçóes a respeito das concepçóes avaliativas; o percurso histórico da educação; pressupostos teóricos e práticos das teorias curriculares; gestão da sala de aula e a atuação docente. $\mathrm{Na}$ intenção de viabilizar o processo de produção textual, preza-se pelo uso de obras científicas que se relacionam à temática.

\section{Metodologia}

Considerando as características dos métodos de estudo, o presente artigo é composto pela investigação exploratória a fim de explanar a importância da temática, também de caráter descritivo por observar, registrar, interpretar e discutir a formação do professor frente às teorias e concepçôes pedagógicas contemporâneas, obviamente, sem interferência nos resultados da pesquisa. Conforme Boccato (2006), esse tipo de pesquisa busca a resolução de um problema por meio de referenciais teóricos publicados, analisando e discutindo as várias contribuiçóes científicas. Também, traz subsídios para o conhecimento sobre o que o assunto pesquisado, como e sob que enfoque e/ou perspectivas tratou-se a temática apresentada na literatura científica.

Segundo Vergara (2007), a pesquisa parte da coleta de informaçóes para um estudo sistematizado desenvolvido com base no levantamento de material publicado em livros, revistas, jornais ou sites. Portanto, o método utilizado nessa proposta correspondeu à pesquisa bibliográfica por conta da fundamentação teórica que se construiu para contextualziar a formação do professor frente às teorias e concepçóes pedagógicas contemporâneas ao longo do artigo, que tem como principal característica "explorar por meio de diferentes autores a essência de um determinado assunto” (LAKATOS, 2007, p. 107). 
A análise bibliográfica considera mais a subjetividade do pesquisador, considerando a totalidade das informaçôes, e não dados ou aspectos isolados" (ALYRIO, 2009, p. 11). Desse modo, para viabilizar o levantamento de informaçóes e a elaboração deste artigo, a metodologia adotou a abordagem qualitativa, uma vez que utilizou-se de estudos de casos e artigos on-lines sobre a formação do professor frente às teorias e concepçóes pedagógicas contemporâneas. Assim, buscou-se analisar minuciosamente todas as informaçóes registradas, interpretando as observaçóes com base nas teorias que sustentaram a revisão bibliográfica da pesquisa.

\section{Referencial teórico}

\subsection{Concepçöes avaliativas: classificatória e formativa}

Incialmente, na intenção de se contextualizar acerca da formação do professor frente às teorias e concepçôes pedagógicas contemporâneas, é preciso compreender sobre a avaliação de aprendizagem, a formativa e a classificatória, evidenciando os pressupostos teóricos e práticos dessas avaliaçóes, que ela ajuda o aluno a compreender e a se desenvolver.

Colabora para a regulação de suas aprendizagens, para o desenvolvimento de suas competências e o aprimoramento de suas habilidades em favor de um projeto. Um professor comprometido com a aprendizagem de seus alunos utiliza os erros, inevitáveis sobretudo no começo, como uma oportunidade de observação e intervenção. Com base neles, propóe situações-problema cujo enfrentamento requer uma nova e melhor aprendizagem, possível e querida para quem a realiza. (MACEDO, 2007, p. 118).

No entanto, para obter essa prática docente crítica, construtiva e formativa, é fundamental que haja uma avaliação feita com qualidade e com o objetivo de formar os educandos para que eles aprendam e se desenvolvam individual e coletivamente. Além disso, se faz necessário uma avaliação fundamentada e que preencha os requisitos previstos na legislação de ensino, pois além de ajudar os alunos no processo ensino e aprendizagem, ela serve também como um sistema de crítica do próprio projeto elaborado pelo professor.

De modo geral, a avaliação tem um olhar crítico, capaz de analisar e verificar em que se deve melhorar nos planos de ação, ou seja, no processo ensino aprendizagem. Para confirmar isso, Luckesi (1996, p. 117) diz que "neste nível, a avaliação é um constante olhar crítico sobre o que se está fazendo. Esse olhar possibilita que se decida sobre os modos de como melhorar a construção do projeto no qual estamos trabalhando.”

Em outras palavras, é possível dizer que a avaliação é um instrumento da prática educativa que permite constatar se os métodos que vêm sendo praticados estão tendo eficácia na consecução dos objetivos propostos. É de grande relevância que o professor discuta com os alunos sobre as atividades propostas para a concretização dos objetivos que se pretende alcançar, pois o processo avaliativo é parte fundamental do fazer pedagógico.

Dessa forma, pode-se perceber duas lógicas do sistema: a avaliação formativa e a classificatória. A mais tradicional e conhecida, voltada às exigências burocráticas é a classificatória, que privilegia as notas dos alunos, valor mínimo exigido para o sucesso ou exclusão do processo. Já a necessária para realmente formar o aluno é avaliação formativa que se volta especificamente à aprendizagem do aluno e continuamente quando o professor lhe confere valores para alcance 
do mínimo exigido legalmente para sua promoção.

Portanto, assevera-se que tais contribuições da avaliação formativa e classificatória oferecem subsídios ao professor para verificar e observar o nível de desenvolvimento dos alunos através de cada uma dessas avaliaçóes é possível utilizá-las como recurso efetivo.

\subsection{Construçáo do percurso histórico da educação na formação docente}

Nóvoa (1996) salienta que é preciso romper com a visão natural da educação, pois a educação é histórica e a ação do homem no tempo não está antecipadamente definida. Considerando esse apontamento, tem-se a necessidade de findar com as reproduçôes em sala de aula gerando assim transformaçóes no processo escolar, pois, segundo Nunes (2003), o papel do professor é ajudar, [...] os estudantes a internalizarem algumas funçóes que ele mesmo aprendeu e desempenha para que seus alunos se tornem, eles próprios, professores de si mesmos.

[...] A organização do pensamento, as habilidades de comparação, análise e síntese, a imaginação pedagógica, a capacidade de seleção da informação e resolução de problema, a construção de uma compreensão e da sua comunicação (NUNES, 2003, p. 117-118).

Percebe-se assim que, a História da Educação faz uma direta ligação entre teoria e prática. Para tal, é necessário pensar nos fatos e dados históricos nos quais estiveram e estão presentes na educação e assim enxergar quais foram as permanências e as mudanças ocorridas nestes momentos históricos. Conforme as palavras de Louro (1990, p.21) "o seu resgate implica, no entanto, perceber seus vínculos teóricos, os questionamentos que impóe, seus limites, suas, potencialidades." Assim, é extremamente relevante que o professor conheça em sua formação sobre a história da educação e suas transformaçôes ao longo das épocas.

\subsection{Pressupostos teóricos e práticos das teorias curriculares: náo crítica, crítica e pós-crítica}

Sem dúvida, a relevância dessa discussão é extremamente importante na análise do currículo e da prática social, dado ao fato de que o currículo faz parte integrante do dia-a-dia das escolas e das instituições de educação superior, e exercerá direta ou indiretamente sua influência nos sujeitos que fazem parte do processo educativo e da sociedade em geral. Segundo Silva (2009), a teoria tradicional de currículo busca a neutralidade, tendo como escopo principal promover a identificação dos objetivos da educação escolarizada, formando o trabalhador especializado ou, proporcionando uma educação geral e acadêmica.

As novas teorias críticas do currículo, preocuparam-se em compreender, baseados na teoria dialética-crítica de Karl Marx (1818-1883), qual era o real papel do currículo na educação. Para Silva (2009, p. 29-30) "[...] as teorias críticas do currículo efetuam uma completa inversão nos fundamentos das teorias tradicionais. As teorias críticas sobre o currículo, em contrate, começam por colocar em questão precisamente os pressupostos dos presentes arranjos sociais e educacionais. As teorias críticas desconfiam do status quo, responsabilizando-o pelas desigualdades e injustiças sociais."

Ademais, de acordo com as teorias críticas do currículo, é o currículo oculto que "ensina, em geral, o conformismo, a obediência, o individualismo" (SILVA, 2009, p. 78) e que mantêm a ideologia dominante. Essa proposta evidencia então o enfoque das teorias tradicionais, críticas e pós-críticas e possibilita perceber a valorização que cada uma faz a partir do que propóe. É 
clara a preocupação da teoria crítica com as classes sociais, com a emancipação, conscientização e libertaçáo dessas classes (trabalhadoras), que são obrigadas a aceitar a condiçáo de aprender na escola a cultura dominante, de um currículo voltado para os interesses da burguesia.

Nesse sentido, "[...] as teorias críticas de currículo, ao deslocar a ênfase dos conceitos simplesmente pedagógicos de ensino e aprendizagem para os conceitos de ideologia e poder, por exemplo, permitiram-nos ver a educação de uma nova perspectiva” (SILVA, 2009, p. 17). O autor acresce ainda que "[...] as teorias tradicionais eram teorias de aceitação, ajuste e adaptação. As teorias críticas são teorias de desconfiança, questionamento e transformação radical” (p. 30).

No que se refere às teorias pós-críticas, essas abordam com ênfase nas preocupaçóes com a diferença, com as relaçôes saber-poder no âmbito escolar, o multiculturalismo, as diferentes culturas raciais e étnicas, enfim, não é uma questão de superação da teoria crítica. No entanto, Silva (2009) comenta que [...] a teoria pós-crítica deve se combinar com a teoria crítica para nos ajudar a compreender os processos pelos quais, através de relaçóes de poder e controle, nos tornamos aquilo que somos. Ambas ensinam, de diferentes formas, que o currículo é uma questão de saber, identidade e poder.

Finalmente, no currículo tradicional, aprender "consiste em adquirir informaçôes que preparem o sujeito intelectual e moralmente para adaptar-se à sociedade" (EYNG, 2007, p. 119). A aprendizagem que é valorizada é a que propicia a formação de reaçôes estereotipadas, de automatismos, denominados hábitos, geralmente isolados uns dos outros e aplicáveis, quase sempre, somente às situaçóes idênticas em que foram adquiridos.

\subsection{Práticas de ensino na oportunização da aprendizagem}

No contexto educacional existe uma ligação entre o sucesso na trajetória dos alunos e a gestão da sala de aula por parte do professor. Assim, é necessário que o docente se responsabilize pelo estabelecimento das estratégias de gestâo da sala de aula. O professor é responsável pelos alunos a quem ensina, mas também pela organização do espaço e do tempo em sala de aula. É o profissional do ensino que define o conteúdo, que seleciona os materiais e o percurso metodológico do processo como um todo, tendo como pressuposto a Base Nacional Comum Curricular.

Defende-se, desse modo, que a valorização dos saberes práticos e das condições cotidianas do processo educativo é fundamental para o entendimento de como se elabora e reelabora o conhecimento, no processo histórico de construçáo do homem e de sua sociedade. É nesse sentido que nasceu o conceito de saber docente que, segundo Monteiro (2001), permite elucidar as relaçóes dos professores com os saberes que dominam para poder ensinar e aqueles que efetivamente ensinam. É um ponto de vista que considera os saberes práticos como fundamentais para a construção da identidade e da competência dos professores.

Nesse contexto, pode-se entender a relevância da gestão da sala de aula como uma atuação significativa, desempenhada por profissionais que devem desenvolver uma gestâo exemplar e significativa. Pode-se afirmar ainda que, a gestão da sala de aula pauta-se em açóes que devem ser desenvolvidas com vista a contribuir com a educação ofertada, devendo o docente atuar de forma a proporcionar benefícios para a educação dos alunos, com foco no processo de ensino e aprendizagem, a partir de uma gestão efetiva e complementar. 


\subsection{A atuaçáo docente para o desenvolvimento das aprendizagens}

De acordo com Libâneo (1990, p. 26) "a didática trata da teoria geral do ensino". Como disciplina é entendida como um estudo sistematizado, intencional, de investigação e de prática. Pimenta et al (2013), corrobora ao dizer que a didática, como área da pedagogia, estuda o fenômeno ensino. As recentes modificaçôes nos sistemas escolares e, especialmente, na área de formação de professores configuram uma explosão didática. Sua ressignificação aponta para um balanço do ensino como prática social, das pesquisas e das transformaçôes que têm provocado na prática social de ensinar.

Masetto (1997, p. 13), infere que "a didática como reflexão é o estudo das teorias de ensino e aprendizagem aplicadas ao processo educativo que se realiza na escola, bem como dos resultados obtidos". Assim, a formação do educador exige uma inter-relação entre a teoria e a prática, sendo que a teoria se ocupa da pesquisa unindo-se com os problemas reais que surgem na prática e, esta, por sua vez, se determina pela teoria.

De acordo com Guimarães (2004, p. 31):

O que deve mover a discussão dessa temática éo empenho na formação profissional, é a convicção de que a educação é processo imprescindível para que o homem sobreviva e se humanize e de que a escola é instituição ainda necessária neste processo, enfim, a relevância dessa temática está na compreensão da urgência, da complexidade e da utopia do projeto de escolarização obrigatória e da qualidade por uma sociedade efetivamente mais democrática.

Os educadores enquanto seres sociais que transformam a realidade quando realizam sua prática, precisam estar conscientes da base teórica, a fim de se orientar por ela ao mesmo tempo em que a teoria se alimenta da prática. Nesse contexto, fica evidente a relevância da didática através de uma atuação docente significativa, pautada por profissionais que devem desenvolver um ensino relevante e com foco em práticas de ensino necessárias à educação de qualidade e com vista a oferecer uma prática educativa cada vez mais eficiente.

\section{Consideraçóes finais}

Com o desenvolvimento da temática, foi possível promover a reflexão sobre a necessidade de o professor conhecer e efetivar teorias que valorizam a formaçáo do pensamento crítico, a partir da participação ativa do aluno no contexto da sala de aula. Um dos pontos de enfoque do artigo, considerou que os indivíduos não nascem educadores, mas tornam-se a medida em que se educam, também no contato com o outro, sendo este um processo permanente de apropriação, mediação e transformação do conhecimento e construção da identidade docente.

Por meio da contextualizaçáa realizada ao logo do texto, notou-se que é necessário que o professor reconheça o fenômeno educativo como um processo relacional, contextual e intencional. Mas ao mesmo tempo, é importante que o mesmo perceba que tal ato não é algo espontâneo na natureza, não é mera aprendizagem natural, que se nutre dos materiais culturais que os rodeiam, mas de uma invenção dirigida, uma construçáo humana que tem sentido e que leva consigo uma seleção de possibilidades, de conteúdo e de caminhos, por exemplo.

Nesse sentido, o desenvolvimento do artigo trouxe informaçóes a respeito das concepçóes avaliativas; o percurso histórico da educação; pressupostos teóricos e práticos das 
teorias curriculares; gestão da sala de aula e a atuação docente. Com base no levantamento de informaçôes realizado, se vê algumas das contribuiçôes significativas para formação profissional, uma vez que lançou luz acerca da importância de promover a contínua reflexão sobre o trabalho desenvolvido pelo pedagogo frente à sala de aula, prezando sempre pelo processo de construção da aprendizagem integral do aluno.

\section{Referências}

ALYRIO, R. D. Métodos e técnicas de pesquisa em administraçáo. Rio de Janeiro: Fundação CECIERJ, 2009.

BOCCATO, V. R. C. Metodologia da pesquisa bibliográfica e o artigo científico como forma de comunicaçáo. Disponível em: <http://arquivos.cruzeirodosuleducacional.edu.br/ principal/old/revista_odontologia/pdf/setembro_dezembro_2006/metodologia_pesquisa_ bibliografica.pdf $>$. Acesso em: 02, jan, 2022.

EYNG, Ana Maria. Currículo Escolar. Curitiba, IBPEX, 2007.

GUIMARÃES, V. S. Formaçáo e professores: Saberes, identidade e profissão. Campinas: Papiros, 2004.

LAKATOS, E. M. Fundamentos de metodologia científica. 5. ed. São Paulo: Atlas, 2007. LIBÂNEO. José Carlos. Didática. São Paulo: Cortez, 1990.

LOURO, Guacira Lopes. A História (Oral) da Educaçáo: Algumas Reflexóes. V.9, N.47, P.21- 28, P.1990.

LUCKESI, Carlos Cipriano. Avaliaçáo da Aprendizagem Escolar. 3 Ed. São Paulo: Cortez, I996.

MACEDO, Lino De. Avaliaçáo na Educaçáo. Marcos Muniz Melo (Organizador). 2007.

MASETTO, M. Didática: A Aula Como Centro. São Paulo: FTD, I997.

NÓVOA, António. História da Educação: Percursos De Uma Disciplina. Lisboa/Portugal. Universidade De Lisboa. Texto Traduzido Em 1996.

NUNES, Clarice. $O$ ensino da história da educaçáo e a produçáo de sentidos na sala de aula. Revista Brasileira de História da Educação, 2003.

PIMENTA, S. G. A Construçáo da Didática: Análise de seus Referenciais. Revista Brasileira de Educação, 2013.

SILVA, T. T. Documentos de Identidade: Uma Introdução às Teorias do Currículo. Belo Horizonte: Autêntica, 2009.

VERGARA, Sylvia Constant. Projetos e Relatórios de Pesquisa em Administraçáo. São Paulo: Atlas, 2007. 